\title{
Design, Synthesis and Anticancer Screening of Novel Pyrazole Derivatives Linking to Benzimidazole, Benzoxazole and Benzothiazole
}

\author{
Mohamed A Abdelgawad ${ }^{1}$, Khaled RA Abdellatif ${ }^{1 *}$ and Osama M Ahmed ${ }^{2,3}$ \\ ${ }^{1}$ Organic Chemistry Department, Faculty of Pharmacy, Beni-Suef University, Beni-Suef, Egypt \\ ${ }^{2}$ Physiology Division, Zoology Department, Faculty of Science, Beni-Suef University, Beni-Suef, Egypt \\ ${ }^{3}$ Faculty of Oral and Dental Medicine, Nahda University, New Beni-Suef City, Beni-Suef, Egypt
}

\begin{abstract}
Substituted aromatic amines were diazotized followed by coupling with malononitrile to afford substituted phenyl hydrazono-malononitrile compounds 2a-c. Compounds 3a-c were prepared through the reaction of substituted phenyl hydrazono-malononitriles 2a-c with phenyl hydrazine, while the reaction of compounds 2a-c with hydrazine hydrate afforded diamino compounds $4 a-c$. The diamino compounds $4 a-c$ was condensed with different substituted aromatic aldehydes to yield $\mathrm{N}$-benzylidine pyrazole diamines $5 \mathrm{a}-\mathrm{i}$. The structure of the newly synthesized compounds was confirmed by IR, ${ }^{1} \mathrm{H}$ NMR, MS spectral data and elemental analysis. Twelve novel compounds 3a-c and 5a-i were screened for their anticancer activities against breast carcinoma (T47D) and human hepatocarcinoma cell lines (Huh7) compared with Doxorubicin. The detailed synthesis, spectroscopic data and anticancer activities of the synthesized compounds were reported.
\end{abstract}

Keywords: Anticancer effects; Benzothiazoles; Benzimidazoles; Benzoxazoles; Pyrazoles

\section{Introduction}

Cancer still remains a mean threat to human health, representing the second leading cause of death worldwide [1]. It is estimated that 13.1 million people will die from cancer in 2030 [2]. Recently, many efforts have been made to develop safe and effective ways of treating this disease and to search for novel chemotherapeutic agents with minimal side effects [1]. In this context, the major challenge is the development of more effective and safe drugs for the treatment of cancer. Through searching in the literature, it was found that benzothiazole derivatives play an important role on designing of new drugs, since they present an interesting pharmacological profile [3], including anti-allergic [4], anti-inflammatory [5], antitumor [6], analgesic [7], antimicrobial [8,9], anthelmintic [10], antileishmanial [11], anticonvulsant [12] activities, also with considerable efficacy as kinase, topoisomerase I/II and transretinoic acid metabolism inhibitors [1]. In addition, pyrazole nucleus is an important pharmacophore with a wide range of therapeutically activities such as antitumor [13], antibacterial, anti-inflammatory [14] and hypotensive [14] efficacies and also acts as ligands for benzodiazepine receptors [15]. In addition, benzoxazole or benzimidazole have variable pharmacological activities like antitubercullosis [16], antioxidant, anthelmintic [17], antimicrobial [18] and anticancer [19] potentials. Keeping this in mind, and in continuation of our previous work on the synthesis of new anticancer agents [20-22], it was aimed in this work to synthesize a new series of heterocyclic compounds bearing pyrazole nucleus linked to benzothiazole, benzoxazole or benzimidazole nucleus and to assess their anticarcinogenic effects against breast carcinoma (T47D) and human hepatocarcinoma cell lines (Huh-7).

\section{Materials and Methods}

\section{Chemistry}

Reactions were routinely monitored by thin-layer chromatography (TLC) on silica gel sheets that precoated with UV fluorescent silica (MERCK 60 F 254) and spots were developed using $I_{2}$ vapour / UV light as visualizing agents. Solvent system was chloroform: methanol (in different ratio). ${ }^{1} \mathrm{H}$ NMR spectra were determined in DMSO- $d_{6}$ solvent with Varian Gemini 300 MHZ Spectrometer. Peak positions were given in parts per million $(\delta)$ downfield the tetramethylsilane as internal standard. IR spectra were recorded on a Shimadzu 435
Spectrometer, using $\mathrm{KBr}$ discs and values were represented in $\mathrm{cm}^{-1}$. GC Mass spectra were run on Shimadzu QP-2010 spectrometer and Mass spectra were run on Hewlett Packard 5988 spectrometer at the Microanalytical Center, Cairo University, Egypt. Melting points were determined on a Griffin instrument and are uncorrected. All reported products showed ${ }^{1} \mathrm{H}$ NMR spectra in agreement with the assigned structures. Elemental analysis was performed at the Micro-analytical Center, Cairo University, Egypt. Compounds 1a-c were prepared according to reported procedures $[23,24]$.

\section{General method for preparation of compounds $2 \mathrm{a}-\mathrm{c}$}

To an ice cooled solution of the corresponding amino compounds $1 \mathrm{a}-\mathrm{c}(0.01 \mathrm{~mol})$ in hydrochloric acid $(2.5 \mathrm{~mL})$ and distilled water $(5$ $\mathrm{mL})$, a solution of sodium nitrite $(0.013 \mathrm{~mol})$ in distilled water $(5 \mathrm{~mL})$ was added portion-wise to a well-stirred cold solution of malononitrile $(0.01 \mathrm{~mol})$ in $50 \%$ aqueous ethanol $(10 \mathrm{~mL})$ containing sodium acetate $(0.9 \mathrm{~g}, 0.011 \mathrm{~mol})$. The reaction mixture was kept in ice for $2 \mathrm{~h}$ and then filtered. The obtained solid was dried and crystallized from ethanol. Physical and spectroscopic data for $2 \mathrm{a}-\mathrm{c}$ are listed below.

2 - $\{$ [ 4- ( 1 H-Benzoimidazol-2-yl) - phenyl] hydrazono $\}$ malononitrile (2a): Yellow color solid; yield, $80 \%$; mp $180-182^{\circ} \mathrm{C}$; IR $\left(\mathrm{KBr}, \mathrm{cm}^{-1}\right): 3408,3218(2 \mathrm{NH}), 3055(\mathrm{CH}$ aromatic), $2221(\mathrm{CN}), 1610$ $(\mathrm{N}=\mathrm{C}) ;{ }^{1} \mathrm{H}-\mathrm{NMR}$ (DMSO-d6) $\delta: 4.44\left(\mathrm{~s}, 1 \mathrm{H}, \mathrm{NH}, \mathrm{D}_{2} \mathrm{O}\right.$ exchangeable); $7.53\left(\mathrm{~d}, 2 \mathrm{H}, \mathrm{Ar} \mathrm{H}, J_{\text {value }}=9 \mathrm{~Hz}\right) ; 7.71\left(\mathrm{~s}, 1 \mathrm{H}, \mathrm{NH}, \mathrm{D}_{2} \mathrm{O}\right.$ exchangeable); 7.74-7.83 (m, $4 \mathrm{H}, \mathrm{Ar} \mathrm{H}) ; 8.34\left(\mathrm{~d}, 2 \mathrm{H}, \mathrm{Ar} \mathrm{H}, J_{\text {value }}=9 \mathrm{~Hz}\right) ; \mathrm{MS}(\mathrm{m} / \mathrm{z}): 286$ $\left(\mathrm{M}^{+}, 80 \%\right)$ 208(100\%); Anal. Found: C, 67.10\%; H, 3.60\%; N, 29.30\%; $\mathrm{C}_{16} \mathrm{H}_{10} \mathrm{~N}_{6}$ Calcd. C, 67.12\%; H, 3.52, \%; N, 29.35\%.

*Corresponding author: Khaled RA Abdellatif, Organic Chemistry Department Faculty of Pharmacy, Beni-Suef University, Beni-Suef, Egypt, Tel: 00201002535444; Fax: 0020822317958; E-mail: khaled.ahmed@pharm.bsu.edu.eg

Received February 11, 2014; Accepted February 26, 2014; Published February 28, 2014

Citation: Abdelgawad MA, Abdellatif KRA, Ahmed OM(2014) Design, Synthesis and Anticancer Screening of Novel Pyrazole Derivatives Linking to Benzimidazole Benzoxazole and Benzothiazole. Med chem S1: 001. doi:10.4172/2161-0444.S1001

Copyright: (C) 2014 Abdelgawad MA, et al. This is an open-access article distributed under the terms of the Creative Commons Attribution License, which permits unrestricted use, distribution, and reproduction in any medium, provided the original author and source are credited. 
2-[(4-Benzoxazol-2-yl-phenyl)hydrazono] malononitrile (2b): Yellow color solid; yield; $70 \%$; $\mathrm{mp} 183-185^{\circ} \mathrm{C}$; IR $\left(\mathrm{KBr}, \mathrm{cm}^{-1}\right)$ : $3425(\mathrm{NH}), 3045\left(\mathrm{CH}\right.$ aromatic), $2224(\mathrm{CN}), 1608(\mathrm{~N}=\mathrm{C}) ;{ }^{1} \mathrm{H}-\mathrm{NMR}$ (DMSO-d6) $\delta: 4.99$ (s, 1H, NH, $\mathrm{D}_{2} \mathrm{O}$ exchangeable); 7.43 (d, 2H, ArH protons, $\left.J_{\text {value }}=8.7 \mathrm{~Hz}\right) ; 7.62-7.78(\mathrm{~m}, 4 \mathrm{H}, \mathrm{Ar} \mathrm{H}) ; 8.25(\mathrm{~d}, 2 \mathrm{H}, \mathrm{ArH}$ protons, $\left.J_{\text {value }}=8.7 \mathrm{~Hz}\right) ; \mathrm{MS}(\mathrm{m} / \mathrm{z}): 287\left(\mathrm{M}^{+}, 68 \%\right), 195(100 \%)$; Anal. Found: C, 66.90\%; H, 3.40\%; N, 24.30\%; $\mathrm{C}_{16} \mathrm{H}_{9} \mathrm{~N}_{5} \mathrm{O}$ Calcd. C, $66.89 \%$; $\mathrm{H}, 3.16 \%$; N $24.38 \%$.

2-[2-(Benzothiazol-2-yl-phenyl)-hydrazono] malononitrile (2c): Yellow color solid; yield; $46 \%$; $\mathrm{mp} 186-188^{\circ} \mathrm{C}$; IR $\left(\mathrm{KBr}, \mathrm{cm}^{-1}\right)$ : $3444(\mathrm{NH}), 3050\left(\mathrm{CH}\right.$ aromatic), $2221(\mathrm{CN}), 1599(\mathrm{~N}=\mathrm{C}) ;{ }^{1} \mathrm{H}-\mathrm{NMR}$ (DMSO-d6): $\delta$ 7.37-7.57 (m, 4H, Ar H); 7.60 (d, 1H, ArH, $J_{\text {value }}=6.9 \mathrm{~Hz}$ ); $7.77\left(\mathrm{~d}, 1 \mathrm{H}, \mathrm{ArH}, J_{\text {value }}=8.4 \mathrm{~Hz}\right), 8-8.08(\mathrm{~m}, 1 \mathrm{H}, \mathrm{ArH}) ; 8.17(\mathrm{~d}, 1 \mathrm{H}$, $\left.\mathrm{ArH}, J_{\text {value }}=7.8 \mathrm{~Hz}\right), 15.15\left(\mathrm{~s}, 1 \mathrm{H}, \mathrm{NH}, \mathrm{D}_{2} \mathrm{O}\right.$ exchangeable); $\mathrm{MS}(\mathrm{m} / \mathrm{z})$ : $303\left(\mathrm{M}^{+}, 100 \%\right)$; Anal. Calcd. for $\mathrm{C}_{16} \mathrm{H}_{9} \mathrm{~N}_{5} \mathrm{~S} ; \mathrm{C}, 63.35 \%$;, $2.99 \% ; \mathrm{N}$, 23.09\%.; Found: C, $63.40 \%$; H, 3.10\%; N, 23.20\%.

\section{General method for preparation of compounds 3a-C}

A mixture of the corresponding phenyl hydrazonomalononitriles $2 \mathrm{a}-\mathrm{c}(0.01 \mathrm{~mol})$ and phenyl hydrazine $(0.011 \mathrm{~mol})$ in DMF $(20 \mathrm{~mL})$ was refluxed for $6 \mathrm{~h}$. The reaction mixture was evaporated under reduced pressure. The residue was washed with water, dried and crystallized from $\mathrm{DMF} / \mathrm{H}_{2} \mathrm{O}$ mixture. Physical and spectroscopic data for $3 \mathrm{a}-\mathrm{c}$ are listed below.

4-\{[4-(1H-Benzoimidazol-2-yl)phenyl $]$ hydrazono $\}$-5-imino1-phenyl-4,5-dihydro- $\mathbf{H}$-pyrazol-3-ylamine (3a): Red color solid; yield; $75 \%$; $\mathrm{mp}>300^{\circ} \mathrm{C}$; IR $\left(\mathrm{KBr}, \mathrm{cm}^{-1}\right): 3395,3344\left(\mathrm{NH}_{2}\right), 3207,3167$ (2 NH), $1614(\mathrm{C}=\mathrm{N}) ;{ }^{1} \mathrm{H}-\mathrm{NMR}$ (DMSO-d6) $\delta: 3.30\left(\mathrm{~s}, 2 \mathrm{H}, \mathrm{NH}_{2}, \mathrm{D}_{2} \mathrm{O}\right.$ exchangeable), 7.19-7.35 (m, 6H, $4 \mathrm{ArH}$ and $2 \mathrm{NH}, \mathrm{D}_{2} \mathrm{O}$ exchangeable), 7.47-7.60 (m, $6 \mathrm{H}\left(5 \mathrm{H}, \mathrm{ArH}\right.$ and $1 \mathrm{H}, \mathrm{D}_{2} \mathrm{O}$ exchangeable), $7.93(\mathrm{~d}, 2 \mathrm{H}$, $\left.J_{\text {value }}=9 \mathrm{~Hz}\right), 8.24\left(\mathrm{~d}, 2 \mathrm{H}\right.$, ArH protons, $\left.J_{\text {value }}=9 \mathrm{~Hz}\right) ; \mathrm{MS}(\mathrm{m} / \mathrm{z}): 394\left(\mathrm{M}^{+}\right.$, 80\%), 77(100\%); Anal. Calcd. for $\mathrm{C}_{22} \mathrm{H}_{18} \mathrm{~N}_{8}$ : C, 66.99\%; $\mathrm{H}, 4.60 \%$; $28.41 \%$; Found: C, $67.20 \%$; H, $4.70 \%$; N, $28.20 \%$.

4-[(4-Benzoxazol-2-yl-phenyl)hydrazono]-5-imino-1-phenyl4,5-dihydro-1H-pyrazol-3-ylamine (3b): Red colour solid; yield; $75 \%$; $\mathrm{mp}>300^{\circ} \mathrm{C}$; IR $\left(\mathrm{KBr}, \mathrm{cm}^{-1}\right): 3424,3346\left(\mathrm{NH}_{2}\right), 3209,3168$ $(\mathrm{NH}), 1608(\mathrm{C}=\mathrm{N}),{ }^{1} \mathrm{H}-\mathrm{NMR}$ (DMSO-d6) $\delta: 6.25$ (s, 2H, $\mathrm{NH}_{2}, \mathrm{D}_{2} \mathrm{O}$ exchangeable); 7.29-7.47 (m, $6 \mathrm{H}, 4 \mathrm{ArH}$ and $2 \mathrm{H}, \mathrm{D}_{2} \mathrm{O}$ exchangeable); 7.50-7.60 (m,4H, ArH); $7.93\left(\mathrm{~d}, 2 \mathrm{H}, J_{\text {value }}=8.7 \mathrm{~Hz}\right) ; 8.05(\mathrm{~d}, 1 \mathrm{H}, \mathrm{ArH}$, $\left.J_{\text {value }}=8.7 \mathrm{~Hz}\right) ; 8.13\left(\mathrm{~d}, 2 \mathrm{H}, \operatorname{ArH}\right.$ protons, $\left.J_{\text {value }}=8.4 \mathrm{~Hz}\right) ; \mathrm{MS}(\mathrm{m} / \mathrm{z}): 395$ $\left(\mathrm{M}^{+}, 100 \%\right)$; Anal. Calcd. for $\mathrm{C}_{22} \mathrm{H}_{17} \mathrm{~N}_{7} \mathrm{O}$; $\mathrm{C}$, $66.82 \% ; \mathrm{H}, 4.33 \%$; $\mathrm{N}$, $24.80 \%$; Found: C, $67.10 \%$; $\mathrm{H}, 4.50 \%$; N, $24.70 \%$.

4-[(2-Benazothiazol-2-yl-phenyl)hydrazono]-5-imino-1phenyl-4,5-dihydro- $1 \mathrm{H}$-pyrazol-3-ylamine (3c): Red color solid; yield; $65 \%$; $\mathrm{mp}>300^{\circ} \mathrm{C}$; IR $\left(\mathrm{KBr}, \mathrm{cm}^{-1}\right)$ : 3463, $3280\left(\mathrm{NH}_{2}\right), 3222,3169$ $(2 \mathrm{NH}), 1600(\mathrm{C}=\mathrm{N}) ;{ }^{1} \mathrm{H}-\mathrm{NMR}$ (DMSO-d6): $\delta 6.65\left(\mathrm{~s}, 2 \mathrm{H}, \mathrm{NH}_{2}, \mathrm{D}_{2} \mathrm{O}\right.$ exchangeable); 7.31-7.54 (m, $5 \mathrm{H}, 3 \mathrm{ArH}$ and $2 \mathrm{H}, \mathrm{D}_{2} \mathrm{O}$ exchangeable); $7.59\left(\mathrm{~d}, 2 \mathrm{H}, \mathrm{ArH}, J_{\text {value }}=8.4 \mathrm{~Hz}\right) ; 7.93\left(\mathrm{~d}, 2 \mathrm{H}, J_{\text {value }}=8.7 \mathrm{~Hz}\right) ; 8.03-8.11(\mathrm{~m}$, $4 \mathrm{H}, \mathrm{ArH}) ; 8.13\left(\mathrm{~d}, 2 \mathrm{H}, \mathrm{ArH}, J_{\text {value }}=7.5 \mathrm{~Hz}\right)$; $\mathrm{MS}(\mathrm{m} / \mathrm{z}): 411\left(\mathrm{M}^{+}, 73 \%\right)$, 77(100\%); Anal. Calcd. for $\mathrm{C}_{22} \mathrm{H}_{17} \mathrm{~N}_{7} \mathrm{~S}$ : C, $64.22 \% ; \mathrm{H}, 4.16 \% ; \mathrm{N}, 23.83 \%$; Found: C, 64.20\%; H, 4.30\%; N, 23.90\%.

\section{General method for preparation of compounds $4 a-c$}

A mixture of the corresponding phenyl hydrazonomalononitrile $2 \mathrm{a}-\mathrm{c}(0.01 \mathrm{~mol})$ and $99 \%$ hydrazine hydrate $(20 \mathrm{~mL})$ was heated under reflux for $6 \mathrm{~h}$. The reaction mixture was cooled and the formed solid was filtered, washed with water, dried and crystallized from DMF/ methanol (1:1). Physical and spectroscopic data for 4a-c are listed below.
4-\{[4-(1H-Benzoimidazol-2-yl)-phenyl]-hydrazono $\}-4 H$ pyrazole-3,5-diamine (4a): Red color solid; yield; $85 \%$; $\mathrm{mp}>300^{\circ} \mathrm{C}$; IR $\left(\mathrm{KBr}, \mathrm{cm}^{-1}\right):$ 3393, $3297\left(\mathrm{NH}_{2}\right), 3182(\mathrm{NH}) 1617(\mathrm{C}=\mathrm{N}) ;{ }^{1} \mathrm{H}-\mathrm{NMR}$ (DMSO-d6) $\delta: 3.34$ (s, 1H, NH, $\mathrm{D}_{2} \mathrm{O}$ exchangeable), 6.33 (br. s, $4 \mathrm{H}$, $2 \mathrm{NH}_{2}, \mathrm{D}_{2} \mathrm{O}$ exchangeable), $6.69\left(\mathrm{~s}, 1 \mathrm{H}, \mathrm{NH}, \mathrm{D}_{2} \mathrm{O}\right.$ exchangeable), 7.20 $\left(\mathrm{d}, 2 \mathrm{H}, \mathrm{ArH}, J_{\text {value }}=8.7 \mathrm{~Hz}\right), 7.51-7.60(\mathrm{~m}, 2 \mathrm{H}, \mathrm{ArH}), 7.61-7.66(\mathrm{~m}$, $2 \mathrm{H}, \mathrm{ArH}), 8.20\left(\mathrm{~d}, 2 \mathrm{H}, \mathrm{ArH}, J_{\text {value }}=8.7 \mathrm{~Hz}\right) ; \mathrm{MS}(\mathrm{m} / \mathrm{z}): 318\left(\mathrm{M}^{+}, 26 \%\right)$, 129(100\%); Anal. Calcd. for $\mathrm{C}_{16} \mathrm{H}_{14} \mathrm{~N}_{8}: \mathrm{C}, 60.37 \% ; \mathrm{H}, 4.43 \% ; \mathrm{N}, 35.20 \%$; Found: C, $60.20 \%$; H, $4.30 \%$; N, 35.10\%.

4-[(4-Benzoxazol-2-yl-phenyl)-hydrazono]-4H-pyrazole-3,5diamine (4b): Red color solid; yield; $65 \%$; m.p. more than $300^{\circ} \mathrm{C}$; IR $\left(\mathrm{KBr}, \mathrm{cm}^{-1}\right)$ : 3394, $3297\left(\mathrm{NH}_{2}\right), 1617(\mathrm{C}=\mathrm{N}) ;{ }^{1} \mathrm{H}-\mathrm{NMR}$ (DMSO-d6) $\delta$ : 3.34 (s, $1 \mathrm{H}, \mathrm{NH}, \mathrm{D}_{2} \mathrm{O}$ exchangeable), 6.30(br. s, $4 \mathrm{H}, 2 \mathrm{NH}_{2}, \mathrm{D}_{2} \mathrm{O}$ exchangeable), $7.40\left(\mathrm{~d}, 2 \mathrm{H}, \mathrm{ArH}, J_{\text {value }}=6.6 \mathrm{~Hz}\right) ; 7.74-7.87(\mathrm{~m}, 4 \mathrm{H}, \mathrm{ArH})$; $8.20\left(\mathrm{~d}, 2 \mathrm{H}, \mathrm{ArH}, J_{\text {value }}=6.6 \mathrm{~Hz}\right) ; \mathrm{MS}(\mathrm{m} / \mathrm{z}): 319\left(\mathrm{M}^{+}, 5.45 \%\right), 55(100 \%)$, Anal. Calcd. for $\mathrm{C}_{16} \mathrm{H}_{13} \mathrm{~N}_{7} \mathrm{O}: \mathrm{C}, 60.18 \% ; \mathrm{H}, 4.10 \% ; \mathrm{N}, 30.70 \%$; Found: $\mathrm{C}$, $60.10 \% ; \mathrm{H}, 4.20 \%$; N, 30.60\%.

4-[(2-Benzothiazol-2-yl-phenyl)-hydrazono]-4H-pyrazole-3,5diamine (4c): Red color solid; yield; $70 \%$; $\mathrm{mp}>300^{\circ} \mathrm{C}$; IR $(\mathrm{KBr}, \mathrm{cm}$ 1): 3330, $3210\left(\mathrm{NH}_{2}\right)$; ${ }^{1} \mathrm{H}-\mathrm{NMR}$ (DMSO-d6): $\delta 6.40$ (br. s, $4 \mathrm{H}, 2 \mathrm{NH}_{2}$, $\mathrm{D}_{2} \mathrm{O}$ exchangeable), $7.42\left(\mathrm{~d}, 2 \mathrm{H}, \mathrm{ArH}, J_{\text {value }}=7.2 \mathrm{~Hz}\right), 7.50-7.58(\mathrm{~m}, 2 \mathrm{H}$, ArH), 7.81-8.05 (m, 2H, ArH), $8.12\left(\mathrm{~d}, 2 \mathrm{H}, \mathrm{ArH}, J_{\text {value }}=7.2 \mathrm{~Hz}\right), 10.80$ (s, $1 \mathrm{H}, \mathrm{NH}, \mathrm{D}_{2} \mathrm{O}$ exchangeable); $\mathrm{MS}(\mathrm{m} / \mathrm{z}): 335\left(\mathrm{M}^{+}, 45 \%\right), 225(100 \%)$; Anal. Calcd. for $\mathrm{C}_{16} \mathrm{H}_{13} \mathrm{~N}_{7} \mathrm{~S}$ : C, 57.30\%; H, 3.91\%; N, 29.23\%; Found: C, $57.10 \%$; H, $4.10 \%$; N, $29.50 \%$.

\section{General procedures for synthesis of compounds $5 \mathrm{a}-\mathrm{i}$}

A mixture of the corresponding pyrazole derivative $4 \mathrm{a}-\mathrm{c}(0.005$ $\mathrm{mol})$ and the appropriate aromatic aldehyde $(0.005 \mathrm{~mol})$ in DMF (25 $\mathrm{mL}$ ) was treated with glacial acetic acid (2 drops) and heated under reflux for $10 \mathrm{~h}$. The reaction mixture was poured into ice-cooled water. The formed precipitate was filtered, dried and crystallized from DMF/ ethanol (1:1) to give compounds 5a-i. Physical and spectroscopic data for $5 \mathrm{a}-\mathrm{i}$ are listed below.

4-\{[4-(1H-Benzoimidazol-2-yl)-phenyl]hydrazono $\}$ - N(4-fluorobenzylidine)-4H-pyrazole-3,5-diamine (5a): Red color solid; yield; $45 \% ; \mathrm{mp}>300^{\circ} \mathrm{C}$; IR $\left(\mathrm{KBr}, \mathrm{cm}^{-1}\right): 3418\left(\left(\mathrm{NH}, \mathrm{NH}_{2}\right), 1629(\mathrm{C}=\mathrm{N})\right.$; ${ }^{1} \mathrm{H}-\mathrm{NMR}$ (DMSO-d6): $\delta 3.60$ (s, 1H, NH, $\mathrm{D}_{2} \mathrm{O}$ exchangeable), 7.43 (d, $\left.2 \mathrm{H}, \mathrm{ArH}, J_{\text {value }}=7.2 \mathrm{~Hz}\right), 7.44\left(\mathrm{~d}, 2 \mathrm{H}, \mathrm{ArH}, J_{\text {value }}=6.9 \mathrm{~Hz}\right) ; 7.74-7.94(\mathrm{~m}$, $4 \mathrm{H}, \mathrm{ArH}) ; 7.99\left(\mathrm{~d}, 2 \mathrm{H}, \mathrm{ArH}, J_{\text {value }}=7.2 \mathrm{~Hz}\right) ; 8.20\left(\mathrm{~d}, 2 \mathrm{H}, \mathrm{ArH}, J_{\text {value }}=6.9\right.$ $\mathrm{Hz}), 8.95\left(\mathrm{~s}, 2 \mathrm{H}, \mathrm{NH}_{2}, \mathrm{D}_{2} \mathrm{O}\right.$ exchangeable), $9.99(\mathrm{~s}, 1 \mathrm{H}, \mathrm{N}=\mathrm{CH}), 10.65$ (s, $1 \mathrm{H}, \mathrm{NH}, \mathrm{D}_{2} \mathrm{O}$ exchangeable); MS (m/z): $424\left(\mathrm{M}^{+}, 14 \%\right)$ 57(100\%); Anal. Calcd. for $\mathrm{C}_{23} \mathrm{H}_{17} \mathrm{FN}_{8}$ : C, 65.09\%; H, 4.04\%; N, 26.40\%; Found: C, $65.10 \%$; $\mathrm{H}, 4.10 \%$; N, 26.30\%.

4-[(4-Benzoxazol-2-yl-phenyl)-hydrazono]- $N$ (4-fluorobenzylidine)- $4 \mathrm{H}$-pyrazole-3,5-diamine (5b): Red color solid; yield; 50\%; mp > 300 $\mathrm{C}$; IR $\left(\mathrm{KBr}, \mathrm{cm}^{-1}\right): 3408\left(\mathrm{NH}, \mathrm{NH}_{2}\right), 1605(\mathrm{C}=\mathrm{N})$; ${ }^{1} \mathrm{H}-\mathrm{NMR}$ (DMSO-d6): $\delta 3.40$ (s, $1 \mathrm{H}, \mathrm{NH}, \mathrm{D}_{2} \mathrm{O}$ exchangeable), 7.41 (d, $\left.2 \mathrm{H}, \mathrm{ArH}, J_{\text {value }}=6.9 \mathrm{~Hz}\right), 7.44\left(\mathrm{~d}, 2 \mathrm{H}, \mathrm{ArH}, J_{\text {value }}=6.6 \mathrm{~Hz}\right), 7.74-7.94(\mathrm{~m}$, $4 \mathrm{H}, \mathrm{ArH}), 7.99\left(\mathrm{~d}, 2 \mathrm{H}, \mathrm{ArH}, J_{\text {value }}=6.9 \mathrm{~Hz}\right), 8.20\left(\mathrm{~d}, 2 \mathrm{H}, \mathrm{ArH}, J_{\text {value }}=6.6\right.$ $\mathrm{Hz}) ; 8.90$ (s, 2H, $\mathrm{NH}_{2}, \mathrm{D}_{2} \mathrm{O}$ exchangeable), 9.96 (s, $\left.1 \mathrm{H}, \mathrm{N}=\mathrm{CH}\right)$; MS $(\mathrm{m} / \mathrm{z}): 425\left(\mathrm{M}^{+}, 18 \%\right), 125(100 \%)$; Anal. Calcd. for $\mathrm{C}_{23} \mathrm{H}_{16} \mathrm{FN}_{7} \mathrm{O}: \mathrm{C}$, 64.94\%; H, 3.79\%; N, 23.05\%; Found: C, 65.10\%; H, 3.90\%; N, 23.20\%.

4-[(2-Benzothiazol-2-yl-phenyl)-hydrazono]- $\mathrm{N}$-(4-fluorobenzylidine)-4H-pyrazole-3,5-diamine $(5 \mathrm{c})$ : Red color solid; yield; $40 \%$; mp > 300 ${ }^{\circ}$; IR $\left(\mathrm{KBr}, \mathrm{cm}^{-1}\right): 3276\left(\mathrm{NH}, \mathrm{NH}_{2}\right), 1596(\mathrm{C}=\mathrm{N})$; ${ }^{1} \mathrm{H}-\mathrm{NMR}$ (DMSO-d6): $\delta 7.47\left(\mathrm{~d}, 2 \mathrm{H}, \mathrm{ArH}, J_{\text {value }}=7.2 \mathrm{~Hz}\right), 7.53(\mathrm{~d}, 2 \mathrm{H}$, $\left.\mathrm{ArH}, J_{\text {value }}=6.9 \mathrm{~Hz}\right) ; 7.81-8.00(\mathrm{~m}, 4 \mathrm{H}, \mathrm{ArH}), 8.09\left(\mathrm{~d}, 2 \mathrm{H}, \mathrm{ArH}, J_{\text {value }}=7.2\right.$ 
$\mathrm{Hz}), 8.17\left(\mathrm{~d}, 2 \mathrm{H}, \mathrm{ArH}, J_{\text {value }}=6.9 \mathrm{~Hz}\right), 9.10(\mathrm{~s}, 1 \mathrm{H}, \mathrm{N}=\mathrm{CH}), 10.40(\mathrm{~s}, 2 \mathrm{H}$, $\mathrm{NH}_{2}, \mathrm{D}_{2} \mathrm{O}$ exchangeable), $11.60\left(\mathrm{~s}, 1 \mathrm{H}, \mathrm{NH}, \mathrm{D}_{2} \mathrm{O}\right.$ exchangeable); $\mathrm{MS}$ $(\mathrm{m} / \mathrm{z}): 441\left(\mathrm{M}^{+}, 11 \%\right)$ 60(100\%); Anal. Calcd. $\mathrm{C}_{23} \mathrm{H}_{16} \mathrm{FN}_{7} \mathrm{~S}: \mathrm{C}, 62.57 \%$; H, 3.65\%; N, 22.21\%; Found: C, 62.70\%; H, 3.80\%; N, $22.40 \%$.

4-\{[4-(1H-Benzoimidazol-2-yl)-phenyl]-hydrazono $\}-\mathrm{N}$-(4chloro-benzylidine)-4H-pyrazole-3,5-diamine (5d): Red color solid; yield; $40 \%$; $\mathrm{mp}>300^{\circ} \mathrm{C}$; IR $\left(\mathrm{KBr}, \mathrm{cm}^{-1}\right): 3309$ (broad band, $\mathrm{NH}$, $\left.\mathrm{NH}_{2}\right), 1585(\mathrm{C}=\mathrm{N}) ;{ }^{1} \mathrm{H}-\mathrm{NMR}$ (DMSO-d6): $\delta 3.88\left(\mathrm{~s}, 2 \mathrm{H}, \mathrm{NH}_{2}, \mathrm{D}_{2} \mathrm{O}\right.$ exchangeable); $4.40\left(\mathrm{~s}, 1 \mathrm{H}, \mathrm{D}_{2} \mathrm{O}\right.$ exchangeable); $7.31(\mathrm{~d}, 2 \mathrm{H}, \mathrm{ArH}$, $\left.J_{\text {value }}=7.8 \mathrm{~Hz}\right) ; 7.67\left(\mathrm{~d}, 2 \mathrm{H}, \mathrm{ArH}, J_{\text {value }}=7.2 \mathrm{~Hz}\right) ; 7.75-7.84(\mathrm{~m}, 4 \mathrm{H}, \mathrm{ArH})$; $7.94\left(\mathrm{~d}, 2 \mathrm{H}, \mathrm{ArH}, J_{\text {value }}=7.8 \mathrm{~Hz}\right) ; 8.31\left(\mathrm{~d}, 2 \mathrm{H}, \mathrm{ArH}, J_{\text {value }}=7.2 \mathrm{~Hz}\right) ; 8.65(\mathrm{~s}$, $1 \mathrm{H}, \mathrm{NH}, \mathrm{D}_{2} \mathrm{O}$ exchangeable); $9.95(\mathrm{~s}, 1 \mathrm{H}, \mathrm{N}=\mathrm{CH}) \mathrm{ppm} ; \mathrm{MS}(\mathrm{m} / \mathrm{z}): 440$ $\left(\mathrm{M}^{+}\right.$, 9\%) 403(100\%); Anal. Calcd for $\mathrm{C}_{23} \mathrm{H}_{17} \mathrm{ClN}_{8} ; \mathrm{C}, 62.66 \% ; \mathrm{H}, 3.89 \%$; N, 25.42\%; Found: C, 62.70\%; H, 3.90\%; N, 25.40\%.

4-[(4-Benzoxazol-2-yl-phenyl)-hydrazono]- $\mathrm{N}$-(4-chlorobenzylidine)-4H-pyrazole-3,5-diamine (5e): Red color solid; yield; $45 \% ; \mathrm{mp}>300^{\circ} \mathrm{C}$; IR $\left(\mathrm{KBr}, \mathrm{cm}^{-1}\right): 3438,3268\left(\mathrm{NH}, \mathrm{NH}_{2}\right), 1592(\mathrm{C}=\mathrm{N})$; ${ }^{1} \mathrm{H}-\mathrm{NMR}$ (DMSO-d6): $\delta 4.38$ (s, 2H, $\mathrm{NH}_{2}, \mathrm{D}_{2} \mathrm{O}$ exchangeable), 7.41 (d, $\left.2 \mathrm{H}, \mathrm{ArH}, J_{\text {value }}=5.7 \mathrm{~Hz}\right), 7.78\left(\mathrm{~d}, 2 \mathrm{H}, \mathrm{ArH}, J_{\text {value }}=7.2 \mathrm{~Hz}\right), 7.94-7.99(\mathrm{~m}$, $4 \mathrm{H}, \mathrm{ArH}) ; 8.22\left(\mathrm{~d}, 2 \mathrm{H}, \mathrm{ArH}, J_{\text {value }}=5,7 \mathrm{~Hz}\right), 8.25\left(\mathrm{~d}, 2 \mathrm{H}, \mathrm{ArH}, J_{\text {value }}=7.2\right.$ $\mathrm{Hz}), 9.00(\mathrm{~s}, 1 \mathrm{H}, \mathrm{N}=\mathrm{CH}), 10.40\left(\mathrm{~s}, 1 \mathrm{H}, \mathrm{NH}, \mathrm{D}_{2} \mathrm{O}\right.$ exchangeable $), 11.60$ (s,1H,NH, $\mathrm{D}_{2} \mathrm{O}$ exchangeable); $\mathrm{MS}(\mathrm{m} / \mathrm{z}): 441\left(\mathrm{M}^{+}, 14 \%\right) 403(100 \%)$; Anal. Calcd. for $\mathrm{C}_{23} \mathrm{H}_{16} \mathrm{ClN}_{7} \mathrm{O}$; C, 62.52\%; H, 3.65\%; N, 22.19\%; Found: C, $62.40 \% ; \mathrm{H}, 3.70 \% ; \mathrm{N}, 22.20 \%$.

4-[(2-Benzothiazol-2-yl-phenyl)-hydrazono]- $\mathrm{N}$-(4-chlorobenzylidine)-4H-pyrazole-3,5-diamine (5f): Red color solid; yield; $45 \% ; \mathrm{mp}>300^{\circ} \mathrm{C}$; IR $\left(\mathrm{KBr}, \mathrm{cm}^{-1}\right): 3283\left(\mathrm{NH}, \mathrm{NH}_{2}\right), 1598(\mathrm{C}=\mathrm{N})$, ${ }^{1} \mathrm{H}-\mathrm{NMR}$ (DMSO-d6): $\delta 7.44\left(\mathrm{~d}, 2 \mathrm{H}, \mathrm{ArH}, J_{\text {value }}=6.6 \mathrm{~Hz}\right), 7.53(\mathrm{~d}, 2 \mathrm{H}$, $\left.\mathrm{ArH}, J_{\text {value }}=8.7 \mathrm{~Hz}\right), 8.04-8.11(\mathrm{~m}, 4 \mathrm{H}, \mathrm{ArH}) ; 8.13\left(\mathrm{~d}, 2 \mathrm{H}, \mathrm{ArH}, J_{\text {value }}=8.7\right.$ $\mathrm{Hz}), 8.16\left(\mathrm{~d}, 2 \mathrm{H}, \mathrm{ArH}, J_{\text {value }}=6.6 \mathrm{~Hz}\right), 8.98(\mathrm{~s}, \mathrm{H}, \mathrm{N}=\mathrm{CH}) ; 10.50(\mathrm{~s}, 2 \mathrm{H}$, $\mathrm{NH}, \mathrm{D}_{2} \mathrm{O}$ exchangeable), $11.65\left(\mathrm{~s}, 1 \mathrm{H}, \mathrm{NH} \mathrm{D}_{2} \mathrm{O}\right.$ exchangeable); MS $(\mathrm{m} / \mathrm{z}): 457\left(\mathrm{M}^{+}, 35 \%\right)$ 157(100\%); Anal. Calcd. for $\mathrm{C}_{23} \mathrm{H}_{16} \mathrm{ClN}_{7} \mathrm{~S}$; C, $60.32 \%$; H, 3.52\%; N, 21.41\%; Found: C, 60.50\%; H, 3.60\%; N, $21.40 \%$.

4-\{[4-(1H-Benzoimidazol-2-yl)-phenyl $]$ hydrazono $\}-N$-(4-nitrobenzylidine)-4H-pyrazole-3,5-diamine (5g): Red color solid; yield; $45 \% ; \mathrm{mp}>300^{\circ} \mathrm{C}$; $\mathrm{IR}\left(\mathrm{KBr}, \mathrm{cm}^{-1}\right): 3410\left(\mathrm{NH}, \mathrm{NH}_{2}\right), 1628(\mathrm{C}=\mathrm{N}) ;{ }^{1} \mathrm{H}-\mathrm{NMR}$ (DMSO-d6): $\delta 3.53$ (s, 1H, NH, $\mathrm{D}_{2} \mathrm{O}$ exchangeable), $7.22(\mathrm{~d}, 2 \mathrm{H}, \mathrm{ArH}$, $\left.J_{\text {value }}=5.4 \mathrm{~Hz}\right), 7.61\left(\mathrm{~d}, 2 \mathrm{H}, \mathrm{ArH}, J_{\text {value }}=5.4 \mathrm{~Hz}\right), 7.85-7.94(\mathrm{~m}, 4 \mathrm{H}, \mathrm{ArH})$; $8.14\left(\mathrm{~d}, 2 \mathrm{H}, \mathrm{ArH}, J_{\text {value }}=6.6 \mathrm{~Hz}\right), 8.22\left(\mathrm{~d}, 2 \mathrm{H}, \mathrm{ArH}, J_{\text {value }}=6.6 \mathrm{~Hz}\right), 8.83(\mathrm{~s}$, $1 \mathrm{H}, \mathrm{N}=\mathrm{CH}), 10.30\left(\mathrm{~s}, 2 \mathrm{H}, \mathrm{NH}_{2}, \mathrm{D}_{2} \mathrm{O}\right.$ exchangeable) $), 11.40(\mathrm{~s}, 1 \mathrm{H}, \mathrm{NH}$, $\mathrm{D}_{2} \mathrm{O}$ exchangeable); MS (m/z): $451\left(\mathrm{M}^{+}, 10 \%\right), 57(100 \%)$; Anal. Calcd. for $\mathrm{C}_{23} \mathrm{H}_{17} \mathrm{~N}_{9} \mathrm{O}_{2}$ : C, 61.19\%; H, 3.80\%; N, 27.92\%; Found: C, 61.30\%; H, $3.90 \%$; N, $27.80 \%$.

4-[ (4-Benzoxazol-2-yl-phenyl)hydrazono]- $N$-(4-nitrobenzylidine)-4H-pyrazole-3,5-diamine $(5 \mathrm{~h})$ : Red color solid; yield; $55 \%$; $\mathrm{mp}>300^{\circ} \mathrm{C}$; IR $\left(\mathrm{KBr}, \mathrm{cm}^{-1}\right): 3408\left(\mathrm{NH}, \mathrm{NH}_{2}\right), 1610(\mathrm{C}=\mathrm{N})$; ${ }^{1} \mathrm{H}-\mathrm{NMR}$ (DMSO-d6): $\delta 7.39$ (d, 2H, ArH, $\left.J_{\text {value }}=8.7 \mathrm{~Hz}\right), 7.63(\mathrm{~d}, 2 \mathrm{H}$, $\left.\mathrm{ArH}, J_{\text {value }}=6.9 \mathrm{~Hz}\right), 7.65-7.96(\mathrm{~m}, 4 \mathrm{H}, \mathrm{ArH}), 8.17\left(\mathrm{~d}, 2 \mathrm{H}, \mathrm{ArH}, J_{\text {value }}=8.7\right.$ $\mathrm{Hz}), 8.30\left(\mathrm{~d}, 2 \mathrm{H}, \mathrm{ArH}, J_{\text {value }}=6.9 \mathrm{~Hz}\right), 9(\mathrm{~s}, 1 \mathrm{H}, \mathrm{N}=\mathrm{CH}), 10.60(\mathrm{~s}, 2 \mathrm{H}$, $\mathrm{NH}_{2}, \mathrm{D}_{2} \mathrm{O}$ exchangeable), $11.60\left(\mathrm{~s}, 1 \mathrm{H}, \mathrm{NH}, \mathrm{D}_{2} \mathrm{O}\right.$ exchangeable); $\mathrm{MS}$ $(\mathrm{m} / \mathrm{z}): 452\left(\mathrm{M}^{+}, 13 \%\right), 55(100)$; Anal. Calcd. for $\mathrm{C}_{23} \mathrm{H}_{16} \mathrm{~N}_{8} \mathrm{O}_{3}$ C, 61.06\%; H, 3.56\%; N, 24.77\%; Found: C, 61.10\%; H, 3.50\%; N, $24.80 \%$.

4-[(2-Benzothiazol-2-yl-phenyl)hydrazono]- $\mathrm{N}$-(4-nitrobenzylidine)-4H-pyrazole-3,5-diamine (5i): Red color solid; yield; $50 \% ; \mathrm{mp}>300^{\circ} \mathrm{C}$ IR $\left(\mathrm{KBr}, \mathrm{cm}^{-1}\right): 3398\left(\mathrm{NH}, \mathrm{NH}_{2}\right), 1604(\mathrm{C}=\mathrm{N})$; ${ }^{1} \mathrm{H}-\mathrm{NMR}$ (DMSO-d6) $\delta: 7.44(\mathrm{~m}, 4 \mathrm{H}, \mathrm{ArH}), 7.75$ (d, 2H, ArH, $J_{\text {value }}=8.4$ $\mathrm{Hz}), 8.06\left(\mathrm{~d}, 2 \mathrm{H}, \mathrm{ArH}, J_{\text {value }}=8.4 \mathrm{~Hz}\right), 8.14\left(\mathrm{~d}, 2 \mathrm{H}, \mathrm{ArH}, J_{\text {value }}=8.7 \mathrm{~Hz}\right)$, $8.34\left(\mathrm{~d}, 2 \mathrm{H}, \mathrm{ArH}, J_{\text {value }}=8.7 \mathrm{~Hz}\right) ; 8.90(\mathrm{~s}, 1 \mathrm{H}, \mathrm{N}=\mathrm{CH}), 10.20\left(\mathrm{~s}, 2 \mathrm{H}, \mathrm{NH}_{2}\right.$,
$\mathrm{D}_{2} \mathrm{O}$ exchangeable), $11.30\left(\mathrm{~s}, 1 \mathrm{H}, \mathrm{NH} \mathrm{D}_{2} \mathrm{O}\right.$ exchangeable); $\mathrm{MS}(\mathrm{m} / \mathrm{z})$; $468\left(\mathrm{M}^{+}, 18 \%\right), 80(100 \%)$; Anal. Calcd. for $\mathrm{C}_{23} \mathrm{H}_{16} \mathrm{~N}_{8} \mathrm{O}_{2} \mathrm{~S} ; \mathrm{C}, 58.97 \% ; \mathrm{H}$, $3.44 \%$; N, 23.92\%; Found: C, 59.10\%; H, 3.40\%; N, 23.80\%.

\section{Antiproliferative activity}

\section{Materials:}

Human tumor cell lines: Human hepatocarcinoma cell lines (Huh-7) and breast carcinoma cell lines (T47D) used in this study were obtained from the American Type Culture Collection (ATCC, Minisota, U.S.A.) through the Tissue Culture Unit, the Egyptian Organization for Biological Products and Vaccines, Vacsera, 51 Wezaret EI Zeraa St., Agouza, Giza, Egypt. The tumor cell lines were maintained at Center for Genetic Engineering, Al-Azhar University, Cairo, Egypt by serial sub-culturing.

Preparation of test compounds: The tested derivatives 1-10 and standard anticancer drug, doxorubicin were prepared by dissolving in dimethylsulfoxide (DMSO) and the prepared stock was stored at $-20^{\circ} \mathrm{C}$. Different concentrations of the compounds $0,6.25,12.5,25,50$, 100 and $200 \mu \mathrm{g} / \mathrm{mL}$ in culture medium were used.

Chemicals: Dimethylsulphoxide (DMSO), Dulbecco's Modified Eagle Medium (DMEM), trypan blue, Fetal Bovine Serum, Penicillin/ Streptomycin antibiotic and Trypsin- EDTA Sigma Aldrich Chemical Co., St. Louis, Mo, U.S.A. Tris buffer was obtained from Applichem, Germany. All chemicals and reagents used in this study are of highest analytical grade.

\section{Methods:}

Reagents and buffers: Cells were maintained in Dulbecco's Modified Eagle Medium (DMEM) with 10\% foetal calf serum, sodium pyruvate, $100 \mathrm{U} / \mathrm{mL}$ penicillin and $100 \mathrm{mg} / \mathrm{mL}$ streptomycin at $37^{\circ} \mathrm{C}$ and $5 \% \mathrm{CO}_{2}$.

Trypan blue dye: $0.05 \%$ of the dye was prepared and used for viability counting.

Fetal Bovine Serum (FBS): 10\% concentration was prepared and used for supplementation of Dulbecco's Modified Eagle Medium (DMEM) prior to use.

Penicillin/ Streptomycin: 100 units/ mL Penicillin/2 mg/mL Streptomycin were used for the supplementation of Dulbecco's Modified Eagle Medium (DMEM) prior to use.

Trypsin- EDTA: $0.25 \%$ solution containing 2.5 g Porcine trypsin was used for the harvesting of cells.

\section{Procedures:}

Maintenance of the human cancer cell lines in the laboratory: A cryotube containing frozen cells was taken out of the liquid nitrogen container and then thawed in a water bath at $37^{\circ} \mathrm{C}$. The cryotube was opened under strict aseptic conditions and its contents were supplied by $5 \mathrm{~mL}$ supplemented medium drop by drop in a $50 \mathrm{~mL}$ sterile falcon tubes. The tube was incubated for 2 hours then centrifuged at $1200 \mathrm{rpm}$ for 10 minutes. The supernatant was discarded and the cell pellet was suspended and Seeded in $5 \mathrm{~mL}$ supplemented medium in T25 Nunclon sterile tissue culture flasks. The cell suspension was incubated and followed up daily the supplemented medium was replaced every 2- 3 days. Incubation was continued until a confluent growth was achieved and the cells were freshly subcultured before each experiment to be in the exponential phase of growth.

Collection of cells by trypsinization: First, the medium was 
discarded. The monolayer cell was washed twice with $5 \mathrm{~mL}$ phosphate buffered saline. All the adherent cells were dispersed from their monolayer by the addition of $1 \mathrm{~mL}$ trypsin solution ( $0.25 \%$ trypsin $\mathrm{w} / \mathrm{v})$ for 2 minutes.

Determination and counting of viable cells: Fifty $\mu \mathrm{L}$ of $0.05 \%$ trypan blue solution was added to $50 \mu \mathrm{L}$ of the single cell suspension. The cells were examined under the inverted microscope using the haemocytometer. Non stained (viable) cells were counted (Viable cells $/ \mathrm{mL}=\left(\right.$ number of cells in 4 quarters $\times 2$ (dilution factor) $\left.\times 10^{4}\right) / 4$ ). The cells were then diluted to give the required cell number for each experiment.

Cryopreservation of cells: To avoid the loss of the cell line, excess cells were preserved in liquid nitrogen as follows:

Equal parts of the cell suspension and freezing medium $(10 \%$ DMSO in supplemented medium) were dispersed to cryotubes.

The cryotubes were racked in appropriately labeled polystyrene boxes, gradually cooled till reaching $-80^{\circ} \mathrm{C}$.

Then the cryotubes were stored in a liquid nitrogen $\left(-180^{\circ} \mathrm{C}\right)$ till use.

\section{Determination of potential cytotoxicity of drug on human cancer cell line}

Principle: The cytotoxicity was carried out using Sulphorhodamine-B (SRB) assay following the method reported by Vichai and Kirtikara, (2006) [25]. SRB is a bright pink aminoxanthrene dye with two sulphonic groups. It is a protein stain that binds to the amino groups of intracellular proteins under mildly acidic conditions to provide a sensitive index of cellular protein content.

Reagants and buffers: Glacial acetic acid: 1\% was used for dissolving the unbound SRB dye.

Sulphorhodamine-B (SRB): $0.4 \%$ concentration was dissolved in $1 \%$ acetic acid was used as a protein dye.

Trichloroacetic acid (TCA): 50\% stock solution was prepared, $10 \%$ solution was used for protein precipitation.

$10 \mathrm{mM}$ tris base (PH 7.4) was used for SRB dye solubilization. It was prepared by dissolving $121.1 \mathrm{gm}$ of tris base in $1000 \mathrm{~mL}$ distilled water and $\mathrm{pH}$ was adjusted by $2 \mathrm{M} \mathrm{HCl}$.

Procedure: Cells will be seeded in 96 well microtiter plates at a concentration of 1000-2000 cells/well, $100 \mu \mathrm{L} /$ well. After $24 \mathrm{~h}$, cells will be incubated for $72 \mathrm{~h}$ with various concentrations of drugs $(0,6.25$, $12.5,25,50,100$ and $200 \mu \mathrm{g} / \mathrm{mL}$ ). For each derivative concentration and doxorubicin, 3 wells were used. The plates were incubated for 72 hours. The medium is discarded. The cells were fixed with $150 \mu \mathrm{l}$ cold trichloroacetic acid $10 \%$ final concentration for 1 hour at $4^{\circ} \mathrm{C}$. The plates were washed with distilled water using (automatic washer Tecan, Germany) and stained with $50 \mu \mathrm{l} 0.4 \%$ SRB dissolved in $1 \%$ acetic acid for 30 minutes at room temperature in dark. The plates were washed with $1 \%$ acetic acid to remove unbound dye and air-dried $(24 \mathrm{~h})$. The dye was solubilized with $150 \mu \mathrm{l} /$ well of $10 \mathrm{mM}$ tris base (PH 7.4) for $5 \mathrm{~min}$ on a shaker at $1600 \mathrm{rpm}$. The optical density (OD) of each well will be measured spectrophotometrically at $490 \mathrm{~nm}$ with an ELISA microplate reader. The mean background absorbance was automatically subtracted and mean values of each derivative and doxorubicin concentration was calculated. The experiment was repeated 3 times.
Calculation: The percentage of cell survival was calculated as follows:

\section{Surviving fraction=O.D. (treated cells)/ O.D. (control cells)}

The $\mathrm{IC}_{50}$ values (the concentrations of derivatives and doxorubicin required to produce $50 \%$ inhibition of cell growth) were also calculated using linear trendline equation.

\section{Results and Discussion}

\section{Chemistry}

The synthesis of the target compounds was summarized in schemes 1 and 2 . The substituted phenyl hydrazono-malononitriles $2 \mathrm{a}-\mathrm{c}$ were synthesized by diazotization of different substituted aromatic amines 1 a-c followed by coupling their diazonium salt with malononitrile in the presence of sodium acetate.

The structure of compounds $2 \mathrm{a}-\mathrm{c}$ was confirmed through ${ }^{1} \mathrm{Hnmr}$ which showed the appearance on single new $\mathrm{D}_{2} \mathrm{O}$ exchangeable peak at $\delta 4.44,4.99$ and $15.15 \mathrm{ppm}$ corresponding to $\mathrm{NH}$ proton. The IR spectrum showed a pronounced peak of $\mathrm{CN}$ group at 2224 to $2221 \mathrm{~cm}^{-1}$. Also in mass spectrum the molecular ion peaks of $2 \mathrm{a}-\mathrm{c}$ were appeared.

Condensation of substituted phenyl hydrazono-malononitriles 2a-c with phenyl hydrazine afforded compounds 3a-c (Scheme 1).

${ }^{1} \mathrm{HNMR}$ of compounds $3 \mathrm{a}-\mathrm{c}$ showed single signals at $\delta 3.30,6.65$ and $6.25 \mathrm{ppm}$ which corresponding to $\mathrm{NH}_{2}$ protons and also $\mathrm{D}_{2} \mathrm{O}$ peaks in aromatic region.

In IR spectrum the peaks appeared from 3463 to $3167 \mathrm{~cm}^{-1}$ which

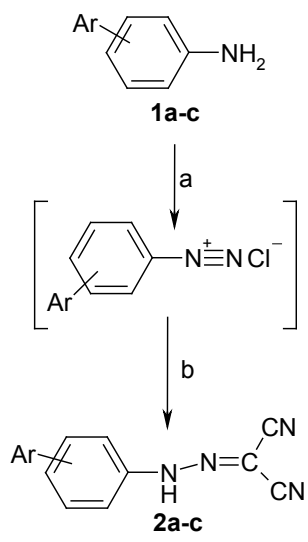<smiles></smiles>

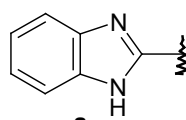

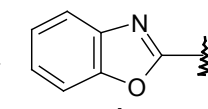

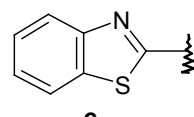

Scheme 1: Reagent and conditions: a) $\mathrm{HCl}, \mathrm{NaNO}_{2}$; b) $\mathrm{CH}_{2}(\mathrm{CN})_{2}$ $\mathrm{Na}$ acetate, aqueous ethanol, $0^{\circ} \mathrm{C}, 2 \mathrm{~h}$; c) Phenyl hydrazine, glacial acetic acid, DMF, reflux, $10 \mathrm{~h}$. 
indicated $\mathrm{NH}$ or $\mathrm{NH}_{2}$, in the same time $\mathrm{CN}$ peak disappeared. Also the mass spectrum of compound $3 \mathrm{a}-\mathrm{c}$ showed the molecular ion peaks.

The respective substituted phenyl hydrazono malononitrile $2 \mathrm{a}-\mathrm{c}$ was heated under reflux with hydrazine hydrate to yield the diamino pyrazole derivatives $4 \mathrm{a}-\mathrm{c}$.

The structure of $4 \mathrm{a}-\mathrm{c}$ was confirmed by ${ }^{1} \mathrm{HNMR}$, IR, mass spectroscopy and elemental analysis.

${ }^{1} \mathrm{HNMR}$ of compounds $4 \mathrm{a}-\mathrm{c}$ showed broad $\mathrm{D}_{2} \mathrm{O}$ exchangeable peak at $\delta 6.33,6.30$ and $6.40 \mathrm{ppm}$ which corresponding to $2 \mathrm{NH}_{2}$ protons.

Also in IR spectrum the forked peaks of $\mathrm{NH}_{2}$ groups were appeared at 3394 to $3210 \mathrm{~cm}^{-1}$ in the same time disappeared of $\mathrm{CN}$ peak. The molecular ion peaks of $4 \mathrm{a}-\mathrm{c}$ appeared in suitable relative intensity.

Heating equimolar amounts of the pyrazole derivatives $4 \mathrm{a}-\mathrm{c}$ with the corresponding aromatic aldehyde in dimethyl formamide containing catalytic amount of glacial acetic acid yielded $N$-benzylidine pyrazole diamine 5a-i (Scheme 2) The structure elucidation of compounds 5a-i was made using HNMR mass, IR and elemental analysis.

The broad $\mathrm{D}_{2} \mathrm{O}$ exchangeable peak of compounds $4 \mathrm{a}-\mathrm{c}$ disappeared and azomethane peak appeared at $\delta 8.83$ to 9.99 in ${ }^{1} \mathrm{HNMR}$ spectrum. The relative intensities of molecular ions of $5 \mathrm{a}-\mathrm{i}$ were showed in mass spectrum.

\section{Antiproliferative activity}

For the evaluation of the anti-tumor cytotoxicity of the synthesized compounds, two different human cancer cell lines, Huh-7 (liver carcinoma cell line) and T47D (breast carcinoma cell line), were used. Cytotoxicity of pyrazol-3-ylamine derivatives 3a-c and pyrazole-3,5diamine derivatives 5a-i against Huh-7 and T47D is shown in Figures 1 and 2, respectively. The $\mathrm{IC}_{50}$ values are found associated with each figure.

Based on the data obtained, all the tested pyrazol-3-ylamine and pyrazole-3,5-diamine derivatives have anti-proliferative potentials on Huh-7 cell lines to various degrees. In general, pyrazole-3,5diamine derivatives $5 \mathrm{a}-\mathrm{i}$ seemed to be more effective in decreasing the survival percent than pyrazol-3-ylamine derivatives 3a-c. Based on their cytotoxic efficacy and $\mathrm{IC}_{50}$, the compounds are arranged in a descending order as follows: compounds $5 \mathrm{~b}\left(\mathrm{IC}_{50}=16.22 \mu \mathrm{g} / \mathrm{mL}\right), 5 \mathrm{a}$ (29.85 $\mu \mathrm{g} / \mathrm{mL}), 5 \mathrm{c}(34.20 \mu \mathrm{g} / \mathrm{mL}), 5 \mathrm{~d}(34.87 \mu \mathrm{g} / \mathrm{mL}), 5 \mathrm{~g}(38.57 \mu \mathrm{g} / \mathrm{mL})$, $5 \mathrm{~h}(53.71 \mu \mathrm{g} / \mathrm{mL}), 5 \mathrm{i}(87.70 \mu \mathrm{g} / \mathrm{mL}), 3 \mathrm{a}(96.00 \mu \mathrm{g} / \mathrm{mL}), 5 \mathrm{f}(100.78 \mu \mathrm{g} /$ $\mathrm{mL}), 5 \mathrm{e}(100.90 \mu \mathrm{g} / \mathrm{mL}), 3 \mathrm{~b}(120.22 \mu \mathrm{g} / \mathrm{mL})$ and $3 \mathrm{c}\left(\mathrm{IC}_{50}=127.17 \mu \mathrm{g} /\right.$ $\mathrm{mL}$ ) (Figure 1).

Figure 2 revealed that compound 3a exhibited the most potent effect in decreasing the survival percent of T47D breast carcinoma cell lines $\left(\mathrm{IC}_{50}=37.02 \mu \mathrm{g} / \mathrm{mL}\right)$. The other tested derivatives are arranged, based on their cytotoxic potencies against T47D and on the obtained $\mathrm{IC}_{50}$, in the following order: derivatives $5 \mathrm{e}\left(\mathrm{IC}_{50}=72.93 \mu \mathrm{g} / \mathrm{mL}\right), 5 \mathrm{c}$ (77.39 $\mu \mathrm{g} / \mathrm{mL}), 5 \mathrm{f}(80.11 \mu \mathrm{g} / \mathrm{mL}), 5 \mathrm{a}(83.79 \mu \mathrm{g} / \mathrm{mL}), 5 \mathrm{~h}(85.35 \mu \mathrm{g} / \mathrm{mL})$, $5 \mathrm{i}(99.27 \mu \mathrm{g} / \mathrm{mL}), 5 \mathrm{~g}(156.80 \mu \mathrm{g} / \mathrm{mL}), 3 \mathrm{~b}(165.78 \mu \mathrm{g} / \mathrm{mL}), 3 \mathrm{c}(174.16 \mu \mathrm{g} /$ $\mathrm{mL}), 5 \mathrm{~d}(201.30 \mu \mathrm{g} / \mathrm{mL})$ and $5 \mathrm{~b}\left(\mathrm{IC}_{50}=233.05 \mu \mathrm{g} / \mathrm{mL}\right)$. Thus, derivative 3a followed by $5 \mathrm{e}$ and $5 \mathrm{c}$ seemed to have the most cytotoxic effects against breast carcinoma cell lines (Figure 2).

The previous report [26] revealed that the benzimidazole derivatives and benzoxazole natural products against lung cancer cell line A549 and breast cancer cell line MCF-7. Benzothiazole derivatives were reported to show growth inhibition against a broad spectrum of human cancer cells and induced apoptosis of HepG2 cells in a dose-

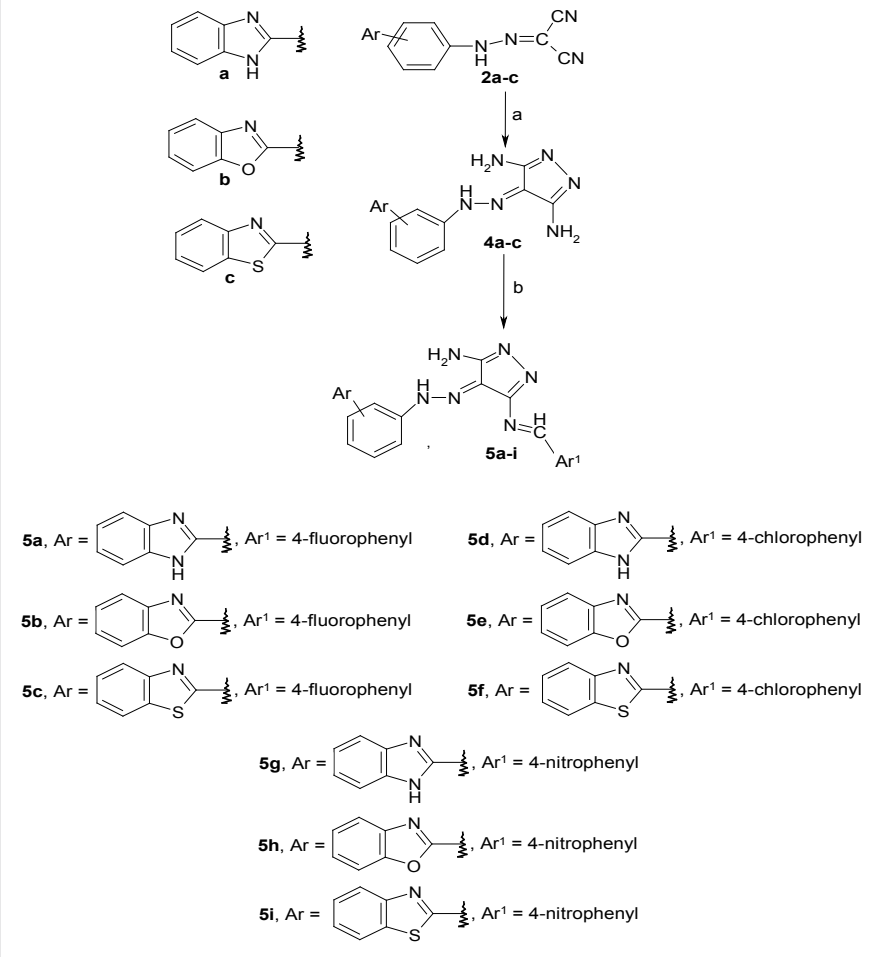

Scheme 2: Reagent and conditions: a) hydrazine hydrate $99 \%$, reflux, $6 \mathrm{~h}$; b) substituted aromatic aldehydes, DMF, glacial acetic acid, reflux, $12 \mathrm{~h}$.

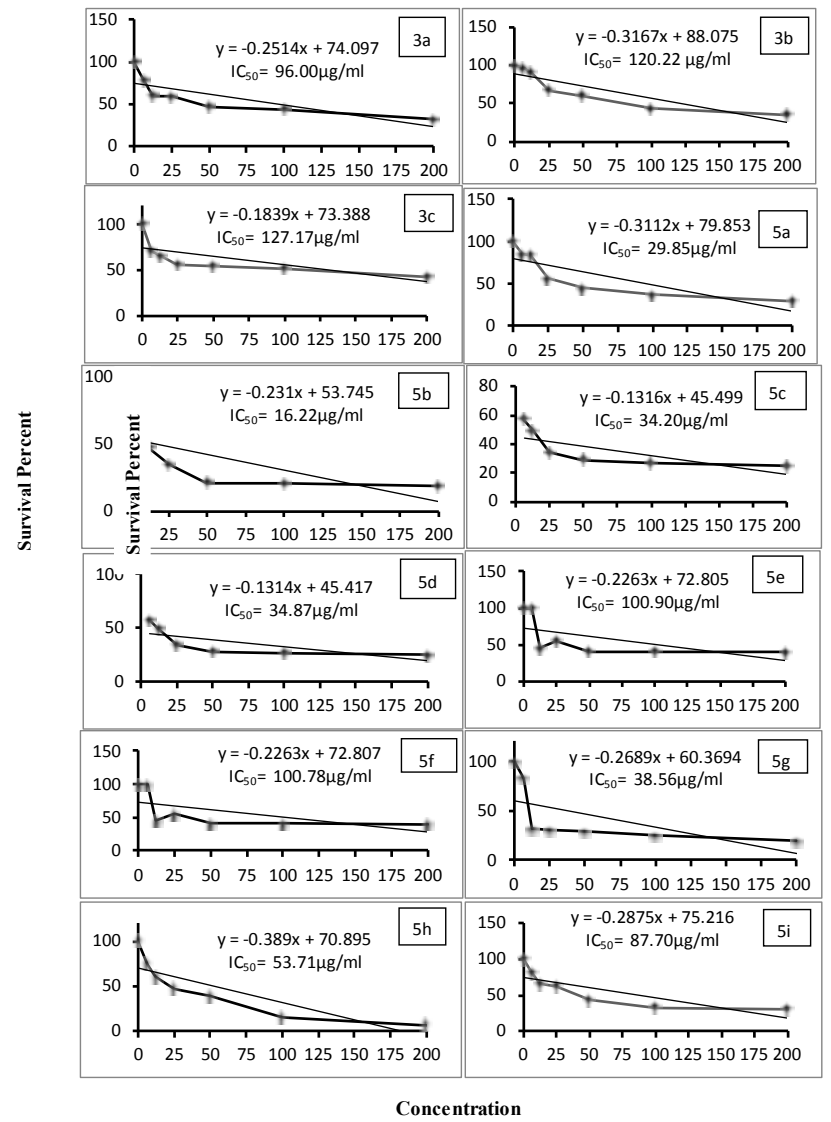

Figure 1: Anti-tumor cytotoxicity of different concentrations $(\mu \mathrm{g} / \mathrm{mL})$ of pyrazol-3-ylamine and pyrazole-3,5-diamine derivatives against human hepatocarcinoma cell lines (Huh-7) in vitro. 


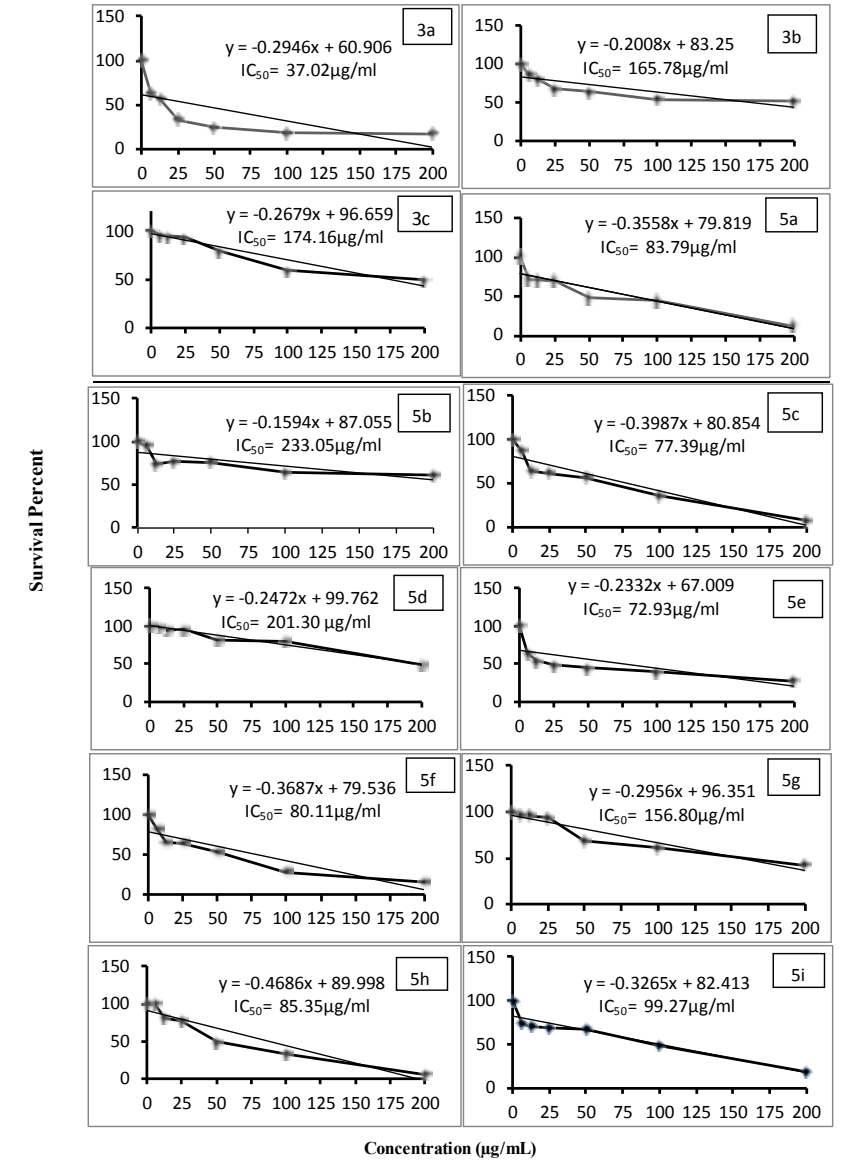

Figure 2: Anti-tumor cytotoxicity of different concentrations $(\mu \mathrm{g} / \mathrm{mL})$ of pyrazol3-ylamine and pyrazole-3,5-diamine derivatives against human breast cell lines (T47D) in vitro.

and time-dependent manner [27,28]. In addition, pyrazole nucleus was revealed to have an important role in producing anti-tumor potencies $[13,29]$. Based on these reports, the linking pyrazole derivatives to benzimidazole, benzoxazole and benzothiazole in the present study may potentiate the anti-tumor efficacies of novel pyrazol-3-ylamine and pyrazole-3,5-diamine derivatives.

In conclusion, he preliminary biological evaluations revealed that the newly synthesized pyrazole derivatives $5 \mathrm{~b}$ showed the potent in vitro antitumor activity against Huh-7 hepatocarcinoma cell lines $(16.22 \mu \mathrm{g} / \mathrm{mL})$, while derivative $3 \mathrm{a}$ was the most effective in decreasing the survival percent of T47D breast carcinoma cell lines $\left(\mathrm{IC}_{50}=37.02 \mu \mathrm{g} /\right.$ $\mathrm{mL}$ ). However, further future studies are required to elucidate the mechanism of action of these antiproliferative derivatives both in vitro and in vivo.

The structure activity relationship of the synthesized compounds based upon the anticancer screening showed that, the activity of the substituted pyrazoles increases upon increasing electron negativity of halogen of phenyl ring as a result, the flouro derivatives $(3 a, 5 b, 5 c)$ and the chloro derivative (5e) showed the pronounced activity.

\section{References}

1. Caleta I, Kralj M, Marjanovic M, Bertosa B, Tomic S, et al. (2009) Novel cyanoand amidinobenzothiazole derivatives: synthesis, antitumor evaluation, and $\mathrm{X}$-ray and quantitative structure-activity relationship (QSAR) analysis. J Med Chem 52: 1744-1756.

2. World Health Organization (WHO).
3. Rana A, Siddiqui N, Khan SA (2007) Benzothiazoles: A new profile of biological activities. Indian J Pharm Sci 69: 10-17.

4. Ban M, Tagushi H, Katsushima T, Takahashi M, Shinoda K, et al. (1998) Novel antiallergic and antiinflammatory agents. Part I: Synthesis and pharmacology of glycolic amide derivatives. Bioorg Med Chem 6: 1069-1076.

5. Oketani K, Nagakura N, Harada K, Inoue T (2001) In vitro effects of E3040, a dual inhibitor of 5-lipoxygenase and thromboxane $A(2)$ synthetase, on eicosanoid production. Eur J Pharmacol 422: 209-216.

6. Yoshida M, Hayakawa I, Hayashi N, Agatsuma T, Oda Y, et al. (2005) Synthesis and biological evaluation of benzothiazole derivatives as potent antitumor agents. Bioorg Med Chem Lett 15: 3328-3332.

7. Westaway SM, Thompson M, Rami HK, Stemp G, Trouw LS, et al. (2008) Design and synthesis of 6-phenylnicotinamide derivatives as antagonists of TRPV1. Bioorg Med Chem Lett 18: 5609-5613.

8. Sharma V, Sharma KV (2009) Eur J Chem 6: 348-356.

9. Sigmundová I, Zahradnik P, Magdolen P, Bujdakova H (2008) Synthesis and study of new antimicrobial benzothiazoles substituted on heterocyclic ring. Arkivoc 8: 183-192

10. Bhusari KP, Khedekar PB, Umathe SN, Bahekar RH, Rao RR (2000) Indian J Heterocycl Chem 9: 275

11. Delmas F, Avellaneda A, Di Giorgio C, Robin M, De Clercq E, et al. (2004) Synthesis and antileishmanial activity of (1,3-benzothiazol-2-yl) amino-9-(10H)acridinone derivatives. Eur J Med Chem 39: 685-690.

12. Jimonet $P$, Francois A, Barreau M, Blanchard JC, Boirean A (1991)Indian J Med Chem42: 2828.

13. Wentland MP, Aldous SC, Gruett MD, Perni RB, Powles RG, et al. (1995) The antitumor activity of novel pyrazoloquinoline derivatives. Bioorg Med Chem Lett 5: $405-410$

14. Paul S, Gupta M, Gupta R, Loupy A (2001) Microwave assisted solvent-free synthesis of pyrazolo[3,4-b]quinolines and pyrazolo[3,4-c]pyrazoles using $\mathrm{p}-\mathrm{TsOH}$. Tetrahedron Lett 42: 3827-3829.

15. Fryer RI, Zhang P, Rios R, Gu ZQ, Basile AS, et al. (1993) Structure-activity relationship studies at the benzodiazepine receptor (BZR): a comparison of the substitutent effects of pyrazoloquinolinone analogs. J Med Chem 36: 16691673.

16. Klimesová V, Kocí J, Waisser K, Kaustová J, Möllmann U (2009) Preparation and in vitro evaluation of benzylsulfanyl benzoxazole derivatives as potential antituberculosis agents. Eur J Med Chem 44: 2286-2293.

17. Satyendra RV, Vishnumurthy KA, Vagdevi HM, Rajesh KP, Manjunatha H, et al. (2011) Synthesis, in vitro antioxidant, anthelmintic and molecular docking studies of novel dichloro substituted benzoxazole-triazolo-thione derivatives. Eur J Med Chem 46: 3078-3084.

18. Padalkar VS, Borse BN, Gupta VD, Phatangare KR Patil VS, et al. (2012) J. Chem

19. Kamal A, Reddy KS, Khan MN, Shetti RV, Ramaiah MJ, et al. (2010) Synthesis DNA-binding ability and anticancer activity of benzothiazole/benzoxazolepyrrolo[2,1-c][1,4]benzodiazepine conjugates. Bioorg Med Chem 18: 47474761.

20. Abdellatif KR, Belal A, Omar HA (2013) Design, synthesis and biological evaluation of novel triaryl (Z)-olefins as tamoxifen analogues. Bioorg Med Chem Lett 23: 4960-4963.

21. AbdellatifKRA, Abdelall EKA,Abdelgawad MA, Ahmed RR,Bakr RB (2014) Org Chem An Indian Journal 10: 157.

22. Gouda AM, Abdelazeem AH2, Arafa ES3, Abdellatif KR4 (2014) Design, synthesis and pharmacological evaluation of novel pyrrolizine derivatives as potential anticancer agents. Bioorg Chem 53C: 1-7.

23. Shi DF, Bradshaw TD, Wrigley S, McCall CJ, Lelieveld P, et al. (1996) Antitumor benzothiazoles. 3. Synthesis of 2-(4-aminophenyl)benzothiazoles and evaluation of their activities against breast cancer cell lines in vitro and in vivo. J Med Chem 39: 3375-3384.

24. Vicini P, Geronikaki A, Anastasia K, Incerti M, Zani F (2006) Synthesis and antimicrobial activity of novel 2-thiazolylimino-5-arylidene-4-thiazolidinones. Bioorg Med Chem14: 3859-3864.

25. Vichai V, Kirtikara K (2006) Sulforhodamine B colorimetric assay for cytotoxicity screening. Nat Protoc 1: 1112-1116. 
Citation: Abdelgawad MA, Abdellatif KRA, Ahmed OM (2014) Design, Synthesis and Anticancer Screening of Novel Pyrazole Derivatives Linking to Benzimidazole, Benzoxazole and Benzothiazole. Med chem S1: 001. doi:10.4172/2161-0444.S1-001

26. Omar MA, Shaker YM, Galal SA, Ali MM, Kerwin SM, et al. (2012) Synthesis and docking studies of novel antitumor benzimidazoles. Bioorg Med Chem 20: 6989-7001.

27. Xuejiao S, Yong X, Ningyu W, Lidan Z, Xuanhong S, et al. (2013) A novel benzothiazole derivative YLT322 induces apoptosis via the mitochondrial apoptosis pathway in vitro with anti-tumor activity in solid malignancies. PLoS One 8: e63900.
28. Kumar R, Kalidhar U, Kaur A, Bajaj J (2012) RJPBCS 3: 167.

29. Ahmed OM, Mohamed MA, Ahmed RR, Ahmed SA (2009) Synthesis and antitumor activities of some new pyridines and pyrazolo [1,5-a] pyrimidines. Eur $\mathrm{J}$ Med Chem 44: 3519-3523.

This article was originally published in a special issue, Cancer Prevention and Therapy handled by Editor(s). Dr. Dong Xiao, University of Pittsburgh School of Medicine, USA 